\title{
A Data Mining Framework for Prevention and Detection of Financial Statement Fraud
}

\author{
Rajan Gupta \\ Research Scholar, Dept. of Computer Sc. \& \\ Applications, Maharshi Dayanand University, \\ Rohtak (Haryana) - India.
}

\author{
Nasib Singh Gill \\ Head, Dept. of Computer Sc. \& Applications, \\ Maharshi Dayanand University, Rohtak (Haryana), \\ India.
}

\begin{abstract}
Financial statement fraud has reached the epidemic proportion globally. Recently, financial statement fraud has dominated the corporate news causing debacle at number of companies worldwide. In the wake of failure of many organisations, there is a dire need of prevention and detection of financial statement fraud. Prevention of financial statement fraud is a measure to stop its occurrence initially whereas detection means the identification of such fraud as soon as possible. Fraud detection is required only if prevention has failed. Therefore, a continuous fraud detection mechanism should be in place because management may be unaware about the failure of prevention mechanism. In this paper we propose a data mining framework for prevention and detection of financial statement fraud.
\end{abstract}

\section{Keywords}

Data mining, predictive data mining, descriptive data mining, fraud risk reduction

\section{INTRODUCTION}

An intentional misstatement of material facts in the books of accounts by the management of a company with the purpose of deceiving investors, creditors is termed as financial statement fraud. This unlawful activity undermines the quality, integrity and reliability of financial reporting process. Fraudulent financial reporting is a very serious economic and social problem around the world. The importance of this problem can be judged by the fact that a number of Chinese companies listed on US stock exchanges have faced accusations of accounting fraud, and in June 2011, the U.S. Securities and Exchange Commission warned investors against investing with Chinese firms listing via reverse mergers. While over 20 US listed Chinese companies have been de-listed or halted in 2011, a number of others have been hit by the resignation of their auditors [1].

The U.S. Security Exchange Commission charged Floridabased Imperiali, Inc. ("Imperali"), its founder, a former officer, and its former auditor for their involvement in a fraudulent disclosure and accounting scheme. The SEC's complaint alleges that between 2005 and 2008, the company founder orchestrated a scheme to use Imperiali, a business development company that he owned and controlled, to defraud investors by making it appear that Imperiali was a successful global corporation with several wholly-owned businesses when in fact it was nothing more than a shell corporation. The complaint alleges that he raised approximately $\$ 2.5$ million using offering materials that included numerous material misrepresentations and omissions, along with fabricated periodic reports filed with the SEC. Among other things, the complaint alleges that those filings overvalued Imperiali's virtually worthless assets at amounts ranging from $\$ 3.5$ million to $\$ 269$ million, and failed to disclose the issuance of millions of shares of restricted stock [2]. Floyds advisory LLC in their report on AAER's issued by SEC found 22 of cases of fraudulent financial reporting in the first quarter ending on March 31, 2012.

The Report to the Nation on Occupational Fraud and Abuse, a study conducted by the Association of Certified Fraud Examiners in 2012, suggests that the typical organization loses $5 \%$ of its revenue to fraud each year. The median loss caused by occupational fraud cases was $\$ 140,000$. More than one - fifth of these cases caused losses of at least $\$ 1$ million. Perpetrators with higher levels of authority tend to cause much larger losses. The median loss among frauds committed by owner / executives was $\$ 573,000$, the median loss caused by managers was $\$ 180,000$ and the median loss caused by employees was $\$ 60,000$. The report by the ACFE also measured the common methods of detecting fraud. Tips and complaints have consistently been the most effective means of detecting frauds $(43.3 \%)$ [3].

Prevention and Detection of financial statement fraud should complement and supplement each other. However, Bologna \& Lindquist [4] states that prevention should take precedence over detection. Auditing procedures are not skilled for prevention and detection of financial statement fraud because it is not their key objective. Moreover, internal auditors should not be held responsible to detect and identify fraudulent financial reporting, since they are expected to provide the information whether the statement is according to the Generally accepted accounting principles or not. Generally, management of an organisation is supposed to be accountable for prevention and detection of financial statement fraud but it is almost always accomplished with the consent or knowledge of management. Failure to detect or prevent financial statement fraud can damage the reputation and the credibility of the audit profession [5]. ACFE's 2012 report to the nation on occupational fraud and abuse states that audits should not be relied upon as an organisations primary fraud detection method. External audits detected only $3 \%$ of the fraud.

Data mining techniques can be used for assisting auditors since data mining can use past cases of fraud to build models to identify and detect the risk of fraud and help in find discovering the reasons behind financial statement fraud. Data Mining is an iterative process within which progress is defined by discovery of knowledge. Data Mining is most 
useful in an exploratory analysis scenario in which there are no predetermined notions about what will constitute an "interesting" outcome [6].

In this paper, we propose a data mining framework for prevention and detection of financial statement fraud. This paper is organised as follows. Section 2 reveals the related work done in the field of fraud risk reduction i.e. prevention and detection of financial statement fraud. Section 3 discuss about the indicators of fraud and anti fraud environment that an organisation must maintain in order to discourage the practice of financial statement fraud. Section 4 proposes a data mining framework for fraud risk reduction followed by conclusion (Section 5).

\section{RELATED WORK}

The nature and threat of financial statement fraud is truly global. The cost of financial statement fraud is very high and it cause acute damage to the reputation of the organisation concerned. In order to detect and prevent fraudulent financial reporting, a number of statistical, artificial intelligence, machine learning and data mining techniques had been used by number of researchers. For instance, Beasley [7] used Logit regression to test the prediction that the inclusion of larger proportions of outside members on the board of directors significantly reduces the likelihood of financial statement fraud with a sample of 150 American firms. They found that non-fraud firms have boards with significantly higher percentages of outside members than fraud firms. Green and Choi [8] presented a neural network fraud classification model employing endogenous financial data. A classification model created from the learned behaviour pattern is then applied to a test sample. Fanning and Cogger [9] also used an artificial neural network to predict management fraud. Using publicly available predictors of fraudulent financial statements, they found a model of eight variables with a high probability of detection. Kirkos [10], carry out an in-depth examination of publicly available data from the financial statements of various firms in order to detect FFS by using Data Mining classification methods. In this study, three Data Mining techniques namely Decision Trees, Neural Networks and Bayesian Belief Networks are tested for their applicability in management fraud detection. Spathis et al [11] compared multi-criteria decision aids with statistical techniques such as logit and discriminant analysis in detecting fraudulent financial statements. Cecchini et al [12] developed a novel financial kernel using support vector machines for detection of management fraud. An innovative fraud detection mechanism is developed by Huang et al. [13] on the basis of Zipf's Law. This technique reduces the burden of auditors in reviewing the overwhelming volumes of datasets and assists them in identification of any potential fraud records. Hoogs et al [14] presents a genetic algorithm approach to detecting financial statement fraud. Cerullo and Cerullo [15] explained the nature of fraud and financial statement fraud along with the characteristics of $\mathrm{NN}$ and their applications. They illustrated how NN packages could be utilized by various firms to predict the occurrence of fraud. Koskivaara [16] proposed NN based support systems as a possible tool for use in auditing. He demonstrated that the main application areas of $\mathrm{NN}$ were detection of material errors, and management fraud. Busta and Weinberg [17] used $\mathrm{NN}$ to distinguish between 'normal' and 'manipulated' financial data. They examined the digit distribution of the numbers in the underlying financial information. Koh and Low [18] construct a decision tree to predict the hidden problems in financial statements by examining the following six variables: quick assets to current liabilities, market value of equity to total assets, total liabilities to total assets, interest payments to earnings before interest and tax, net income to total assets, and retained earnings to total assets. Belinna et al [19] examine the effectiveness of CART on identification and detection of financial statement fraud. They concluded by saying that CART is a very effective technique in distinguishing fraudulent financial statement from non fraudulent. Juszczak et al. [20] apply many different classification techniques in a supervised two-class setting and a semi-supervised one-class setting in order to compare the performances of these techniques and settings. Further, Deshmukh and Talluru [21] demonstrated the construction of a rule-based fuzzy reasoning system to assess the risk of management fraud and proposed an early warning system by finding out 15 rules related to the probability of management fraud. Zhou \& Kapoor [22] examine the effectiveness and limitations of data mining techniques such as regression, decision trees, neural network and Bayesian networks. They explore a self - adaptive framework based on a response surface model with domain knowledge to detect financial statement fraud. Ravisankar et al [23] uses data mining techniques such as Multilayer Feed Forward Neural Network (MLFF), Support Vector Machines (SVM), Genetic Programming (GP), Group Method of Data Handling (GMDH), Logistic Regression (LR), and Probabilistic Neural Network (PNN) to identify companies that resort to financial statement fraud. They found that PNN outperformed all the techniques without feature selection, and GP and PNN outperformed others with feature selection and with marginally equal accuracies. Recently, Johan Perols [24] compares the performance of six popular statistical and machine learning models in detecting financial statement fraud. The results show, somewhat surprisingly, that logistic regression and support vector machines perform well relative to an artificial neural network in detection and identification of financial statement fraud.

Several researchers had proposed frameworks for detection and prevention of financial statement fraud. For instance, Jans et al [25] present a framework for internal fraud risk reduction. Ngai et al [26] suggested a classification framework for financial fraud detection which consists of two layers. The first comprising the six data mining application classes of classification, clustering, prediction, outlier detection, regression, and visualization supported by second layer which consists of a set of algorithmic approaches to extract the relevant relationships in the data. Recently, Sharma \& Panigrahi [27] propose a data mining framework for detection of financial fraud.

The review of the academic research till date revels that most of the research has been done in the field of identification and detection of financial statement fraud. Data mining has been used extensively for classifying organisations in to fraud or non - fraud. In this study, we proposes a data mining framework which suggests the use of predictive data mining techniques for identification and detection of financial statement fraud and implementation of descriptive data mining for preventing fraudulent financial reporting.

\section{PREVENTION OF FINANCIAL STATEMENT FRAUD}

Financial statement fraud may be defined as a deliberate act of misstating the material facts in the accounting books designed by the management with an aim of injuring capital market participants in terms of financial loss. Management should continually evaluate its anti fraud programs and indicators of fraud for successful fraud prevention. Indicators of fraud are the clues that may warrant further review of a specific area or activity. Some Indicators of fraud are mentioned below [28]: 
1. No separation of duties

2. Lack of internal controls

3. High turnover of personnel

4. Unexplained entries or altered records

5. Unusually large amount of payment for cash

6. Inadequate or missing documentation

7. Non - serial number transactions

8. Unauthorised transactions

The above stated occurrences are indicators of fraud which can often lead to opportunities to commit fraud. The incident of fraudulent financial reporting is possible by an employee / manager who have the adequate opportunity and sufficient motive to misstate the numbers in the books of accounts. In order to prevent financial statement fraud, management of an organisation should assess the above mentioned risk factors continuously. Every organisation should implement anti fraud controls for creating a work environment that values honesty and empower the fraud prevention program. Anti fraud environment will help the organisations in deterring and preventing fraudulent financial reporting. Anti fraud control includes the following [29]:

1. Establish an appropriate tone at the top.

2. Maintain an adequate and effective system of checks and balances

3. Develop effective corporate governance.

4. Ensure a responsible and accountable board of directors.

5. Hire an objective and independent auditing firm.

6. Establish an independent whistle - blower system.

7. Maintain an independent and effective internal audit.

Tone at the top refers to the atmosphere that is created in the workplace by an organisations leadership. The theory is that management's tone will trickle down through the organization. If management acts ethically and with integrity, it is more likely that others in the organization will do the same. In addition, the tone at the top also creates an expectation and reflects the organisation's overall culture. To set the tone, managers need to follow four steps [30]:

1. Communicate the organisation's ethical expectations.

2. Lead by example.

3. Provide a safe mechanism for reporting violations.

4. Reward integrity.

The tone at the top is about creating a fair work culture, an ethical atmosphere, a good working environment which means offering a safe and sound workplace, employing honest individuals and paying them competitive pay packages. The U.S. National Commission on Fraudulent Reporting (1987) highlighted that the tone at the top plays a crucial and influential role in creating an environment in which fraudulent financial reporting is ripe to take place [31]. However, if the management is appeared to be unconcerned about the ethical atmosphere at the top then individuals at the bottom line will be more prone to commit fraud and will create an entire culture of workplace fraud.

\section{FRAMEWORK FOR FINANCIAL STATEMENT FRAUD RISK REDUCTION}

Aggressive or intimidating management style, poor supervision and inadequate segregation of duties are some of the important indicators of weak control environment that may lead to fraudulent financial reporting. The detection of accounting fraud using traditional internal audit procedures is a difficult or impossible task [32]. In general, auditors have no or very little knowledge about the internal control environment of the organisation, thus incapable in preventing and detecting financial statement fraud. In most of cases of fraud, CEO's and other top level executives are found indulged in unlawful practice of fraud because they have enough trust and capability of deceiving auditors. The above mentioned limitations suggest that there is a need of some data mining model or framework for successful financial statement fraud risk reduction.

Data mining is known as gaining insights and identifying interesting patterns from the data stored in large databases in such a way that the patterns and insights are statistically reliable, previously unknown, and actionable [33]. Data mining is also define as -a process that uses statistical, mathematical, artificial intelligence and machine learning techniques to extract and identify useful information and subsequently gaining knowledge from a large database [34]. The data mining techniques have the potential to solve the contradiction between effect and efficiency of fraud detection [35]. Auditing firms and procedures can never become certain about the objective of the management behind a fraudulent transaction. Concerning this reality, data mining as an analytical tool may assist the auditors in prevention and detection of financial statement fraud.

In view of the above, we propose a data mining framework not only for detection but also for prevention of financial statement fraud. The framework is presented as Fig 1. Framework starts with a very important stage of Feature selection. Features includes, financial ratios related to profitability, liquidity, safety and efficiency along with behavioural characteristics such as age of the company, size of the company on the basis of revenue and assets for prevention and detection of financial statement fraud. On the basis of the features mentioned above, we recommend 62 financial ratios / items (Table 1).

Table 1: Features for prevention and detection of financial statement fraud

\begin{tabular}{|c|l|}
\hline S.No. & Financial items / Ratios \\
\hline 1 & Debt \\
\hline 2. & Total assets \\
\hline 3 & Gross profit \\
\hline 4 & Net profit \\
\hline 5 & Primary business income \\
\hline 6 & Cash and deposits \\
\hline 7 & Accounts receivable \\
\hline 8 & Inventory/Primary business income \\
\hline 9 & Inventory/Total assets \\
\hline 10 & Gross profit/Total assets \\
\hline 11 & Net profit/Total assets \\
\hline 12 & Current assets/Total assets \\
\hline 13 & Net profit/Primary business income \\
\hline 14 & Accounts receivable/Primary business income \\
\hline 15 & Primary business income/Total assets \\
\hline 16 & Current assets/Current liabilities \\
\hline 17 & Primary business income/Fixed assets \\
\hline 18 & Cash/Total assets \\
\hline 19 & Inventory/Current liabilities \\
\hline 20 & Total debt/Total equity \\
\hline
\end{tabular}




\begin{tabular}{|c|c|}
\hline 21 & Long term debt/Total assets \\
\hline 22 & Net profit/Gross profit \\
\hline 23 & Total debt/Total assets \\
\hline 24 & Total assets/Capital and reserves \\
\hline 25 & Long term debt/Total capital and reserves \\
\hline 26 & Fixed assets/Total assets \\
\hline 27 & Deposits and cash/Current assets \\
\hline 28 & Capitals and reserves/Total debt \\
\hline 29 & Accounts receivable/Total assets \\
\hline 30 & Gross profit/Primary business profit \\
\hline 31 & Undistributed profit/Net profit \\
\hline 32 & $\begin{array}{l}\text { Primary business profit/Primary business profit of } \\
\text { last year }\end{array}$ \\
\hline 33 & $\begin{array}{l}\text { Primary business income/Last year's primary } \\
\text { business income }\end{array}$ \\
\hline 34 & Account receivable /Accounts receivable of last year \\
\hline 35 & Total assets/Total assets of last year \\
\hline 36 & Debit / Equity \\
\hline 37 & Accounts Receivable / Sales \\
\hline 38 & Inventory / Sales \\
\hline 39 & Sales - Gross Margin \\
\hline 40 & Working Capital / Total Assets \\
\hline 41 & Net Profit / Sales \\
\hline 42 & Sales / Total Assets \\
\hline 43 & Net income / Fixed Assets \\
\hline 44 & Quick assets / Current Liabilities \\
\hline 45 & Revenue/Total Assets \\
\hline 46 & Current Liabilities / Revenue \\
\hline 47 & Total Liability / Revenue \\
\hline 48 & Sales Growth Ratio \\
\hline 49 & EBIT \\
\hline 50 & $\mathrm{Z}-$ Score \\
\hline 51 & Retained Earnings / Total Assets \\
\hline 52 & EBIT / Total Assets \\
\hline 53 & Total Liabilities / Total assets \\
\hline 54 & Cash return on assets \\
\hline 55 & Interest expense / Total Liabilities \\
\hline 56 & EBIT / sales \\
\hline 57 & $\begin{array}{l}\text { Age of the company (Number of years since first } \\
\text { filing available from provider) }\end{array}$ \\
\hline 58 & Change in cash scaled to total assets \\
\hline 59 & Change in current assets scaled by current liabilities \\
\hline 60 & Change in total liabilities scaled by total assets \\
\hline 61 & Size of company on the basis of assets \\
\hline 62 & Size of company on the basis of revenue \\
\hline
\end{tabular}

During the second step of Data Collection, all the financial ratios of Table 1 should be collected from published financial statements namely balance sheet, income statement and cash flow statement. These financial statements may be obtained from various sources such as stock exchange, industry trade journals, newspapers, business periodicals and internet. Data about fraudulent history of the organisation may be collected by analysing Accounting and Auditing Enforcement Releases (AAER's) issued by U.S. Security Exchange Commission.

Once the data collection is over, the dataset need to be made ready for mining by applying various techniques of data preprocessing as the next step. Data preprocessing is also coined as manipulation and enrichment of data by some authors [36]. Data preprocessing includes cleaning, integration and transformation of data. Generally data preprocessing includes appropriate treatment to the missing values, normalization of the input variables and resolving inconsistencies in the dataset.

Now, data is ready for mining, hence the next important module of this framework is selection of appropriate data mining technique. This step is the heart of this framework because at this stage we will decide about the suitable method for mining. Data mining methods can be broadly divided into two subgroups: Predictive and Descriptive techniques. Predictive data mining analyses the data in order to construct one or a set of models, and attempts to predict the behaviour of new data set whereas Descriptive data mining describes the dataset in a concise and summative manner and presents interesting general properties of data [37].

The objective of predictive data mining is to forecast the value of one attribute on the basis of values of other attributes. This capability of predictive data mining will be used for detection of financial statement fraud. One of the important methods of predictive data mining is classification. Classification is a two step process. During the first step, each organisation in the training sample is labelled as fraud or non fraud on the basis of class label attribute. This step of supervised learning results in a model which follows second step of classification in which learned model attempts to classify organisations from validation sample as fraudulent or non fraudulent. Hence, detection and identification of financial statement fraud can be considered as a classical problem of classification.

Descriptive data mining aims at finding correlations among number of attributes in large dataset. The objective of descriptive data mining is to describe the interesting properties of dataset in a summative and concise manner. Descriptive data mining is very easy to apply on unsupervised data. This nature suggests the use of descriptive data mining methods for prevention of financial statement fraud because unsupervised methods detect errors / mistakes, change in behaviour and outlier values instead of classifying organisations as fraud or non fraud. Association rule mining is one of the important methods of descriptive data mining. The process of generation of association rules is divided into two steps. In the first step, minimum support is applied to find frequent itemsets from the dataset. These frequent itemsets along with the constraint of minimum confidence are used for creating association rules in the second step.

The rule engine module of our framework mines the dataset for generating association rules. In the process of association rule generation rule engine first find the frequent itemset. These frequent itemsets are used for creating the association rules which satisfy the minimum support and minimum confidence.

The rule monitor module monitors financial ratios of each organisation and compare the values of the ratios with the values given in the association rules for indicating the anomaly. If value of the financial ratio is greater than the suspicious level, then rule monitor will raise an alarm regarding financial statement fraud.

Management fraud majorly includes three features namely opportunity, rationalisation and motive, which are supposed to be present in various forms in the organisations engaged in unlawful activity of fraudulent financial reporting [38]. These three characteristics are mentioned below.

Opportunity is a situation that provides a chance for an employee / manager to present a rosy picture of financial statement to the capital market participants. For instance, a top 
level executive in a position of trust and who is familiar with the organisation's accounting procedures, weakness and strengths of internal control has a significant opportunity to commit fraud. The opportunity that may lead to financial statement fraud generally provided through weak or nonexistent internal control, complex organizational structure, absence of proper audit committee and improper oversights by board of directors. Inadequate supervision and review and no segregation of duties are some of the examples of weak internal control.

Rationalisation is the ability of an individual to develop an explanation for his unethical activity. The perpetrators of financial statement fraud easily find a way to rationalise their actions and make it acceptable for them. Manager may rationalize their fraudulent behaviour by stating a reason that they are misstating the financial statements in favour of shareholders.

Motive (incentive) is a pressure that a manager may experience for deliberate misstatement of numbers in the accounting books. Pressure can be imposed on managers because of personal financial problems, unrealistic deadlines, idealistic performance goals and personal vices such as gambling, drugs etc.

According to Albrecht et al.'s "fraud scale", opportunity is an element of influence on fraud risk. Being able to select those cases where procedures are circumvented or mistakes are made, is an important contribution to taking away this opportunity and hence to prevent future fraud. The way in which this is dealt with, is up to the company [39]. Hence, prevention of financial statement fraud is primarily based on checking or taking away the opportunity to commit fraud and by avoiding the combination of opportunity, pressure and motive in an organisation.

Financial statement fraud occurs for number of reasons, which can be explained by three variables: conditions, capital structure and choice [40]. The financial statement fraud could be prevented by assuring that these three variables are not present in the organisation. Since, the pattern exhibited by a certain combination of two or more of these variable could provide enough opportunity, motivations and incentives for management to issue fraudulent financial reports. These three variables are explained below:

Condition refers to the motivation and pressure. The management of an organisation may exhibit certain financial pressures. Financial pressure includes pressure to meet analysts' earnings estimate, decline in quantity and quality of earnings etc. Availability of such pressures acts as a motivation for the upper management of an organisation to misstate the financial statements.

Capital structure refers to the working environment created by the organisation. Capital structure means presence of effective corporate governance. Irresponsible and ineffective corporate governance could increase the chances of financial statement fraud. Aggressiveness, arrogance, cohesiveness, loyalty and blind trust are the attributes of corporate governance structure which are associated with financial statement fraud.

Choice is an option to be exercised by the management between the use of ethical business strategies and the use of illegal earnings management schemes for achieving the continuous enhancement in quantity and quality of earnings. Financial statement fraud could be just one of the choices opted by the management. Management of an organisation may choose to engage in fraudulent financial reporting because the probability of detection of fraud is perceived to be very low.

The management of an organisation may use financial statement fraud as a strategic tool in spite of creating a work environment that values honesty. Hence financial statement fraud could be prevented by considering the presence or absence of these variables.

Fundamental aspect of machine learning is evaluating the performance of the data mining techniques. Therefore, Performance evaluation is the final stage of this framework. This step will act as a yardstick for examining the performance and efficiency of data mining methods. A number of evaluation methods such as computational complexity or comprehensibility are available. Every data mining technique has one or the other metric for its performance evaluation. The most commonly used techniques of performance evaluation for classification methods are sensitivity, specificity and confusion matrix and for association rules are support, confidence, lift and conviction. This step is of utmost importance for selecting best suitable technique from a given set of data mining methods and for refining elements of input vector in the iterative process of machine learning. Therefore, result of this step will work as a feedback for the complete framework. 


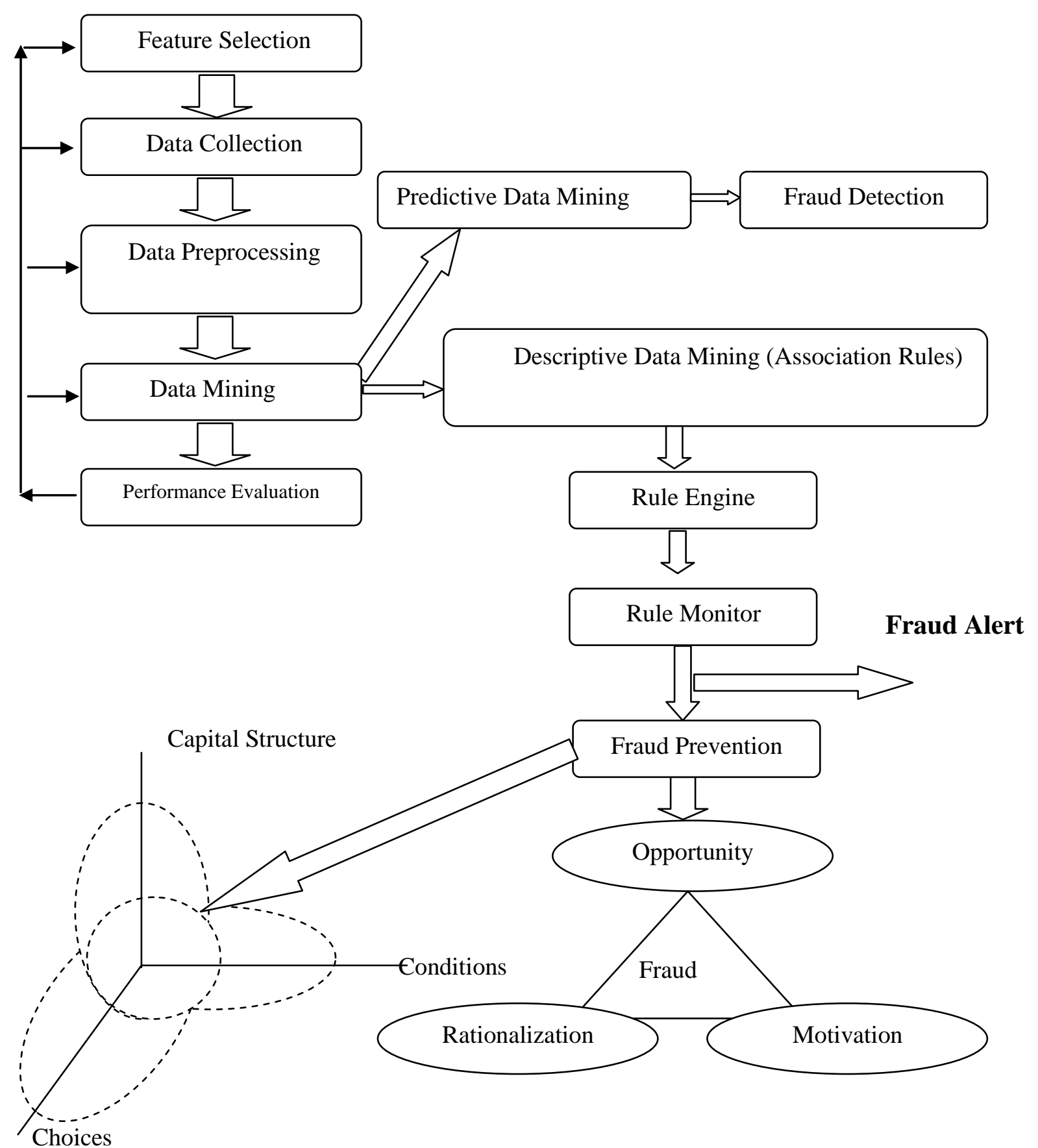

Figure 1: A Framework for Financial Statement Fraud Risk Reduction

\section{CONCLUSION}

The presence of unexpected deviations or outliers in the financial statement fraud is most likely the indicators of errors, but may also indicate unethical, illegal act of fraud. The perpetrators of financial statement fraud show signs of behavioural characteristics such as living beyond one's means, high personnel turnover. Traditional auditing procedures will not be able to identify these factors and hence unable to prevent financial statement fraud at the first place. In view of the fact that victim organisations are unable to recover their losses, cost effective measures to prevent fraud are critical. The substantial cost of financial statement fraud and considerable threat to the economy of a country inspires us to deduce a data mining framework for prevention and detection of financial statement fraud.

In this conceptual paper, we reviewed the academic literature concerning prevention and detection of financial statement 
fraud. We begin with analysing the indicators of financial statement fraud followed by necessity of anti fraud environment which should be maintained by every organisation in order to maintain a tone at the top. In order to prevent financial statement fraud, managers, employees and auditors should be educated on the usage of analytical tools such as data mining.

Considering the dire need of analytical tool for prevention and detection of financial statement fraud, we presented a data mining framework for financial statement fraud risk reduction. This framework has following major contributions. The core of this framework is data mining as it follows the traditional information flow of data mining. Our framework recommends the use of association rules, a descriptive data mining technique, for preventing fraudulent financial reporting along with the use of predictive data mining techniques such as classification for successful identification and detection of financial statement fraud. Rule engine module of our framework will generate interesting association rules, which will be used by rule monitor in order to raise an alarm regarding financial statement fraud. Hence, our framework is capable of preventing the fraudulent financial reporting at the first place and detection of fraud once prevention mechanism is failed.

\section{REFERENCES}

[1]Atkins Matt, Accounting Fraud in US listed Chinese companies (September 2011). Available at: http://www.financierworldwide.com

[2] Floyd Advisory LLC, Summary of Accounting and auditing enforcement releases for three months ended March 31, 2012.

[3] ACFE, 2012 ACFE Report to the nations on ocupational fraud and abuse, Technical report- Global fraud survey 2012, 2012.

[4] Bologna G. And Lindquist R. Fraud Auditing and Forensic Accounting. John Wiley \& Sons, 1995

[5] Chui, L., and B. Pike. 2011. Auditors' responsibility for fraud detection: New wine in old bottles? In Proceedings of the American Accounting Association 2011 Annual Meeting.Denver.

[6] Kantardzi c M. (2002), Data Mining: Concepts, Models, Methods, and Algorithms', Wiley - IEEE Press.

[7] Beasley, M. (1996). An empirical analysis of the relation between board of director composition and financial statement fraud. The Accounting Review, 71(4), 443466.

[8] Green, B. P., \& Choi, J. H. (1997). Assessing the risk of management fraud through neural-network technology. Auditing: A Journal of Practice and Theory, 16(1), 1428.

[9] Fanning, K., \& Cogger, K. (1998). Neural network detection of management fraud using published financial data. International Journal of Intelligent Systems in Accounting, Finance \& Management, 7(1), 21-24.

[10] Efstathios Kirkos, Charalambos Spathis \& Yannis Manolopoulos (2007). Data mining techniques for the detection of fraudulent financial statements. Expert Systems with Applications 32 (23) (2007) 995-1003
[11] C. Spathis, M. Doumpos, C. Zopounidis, Detecting falsified financial statements: a comparative study using multicriteria analysis and multivariate statistical techniques, European Accounting Review 11 (3) (2002) 509-535.

[12] M. Cecchini, H. Aytug, G.J. Koehler, and P. Pathak. Detecting Management Fraud in Public Companies. http://warrington.ufl.edu/isom/docs/papers/DetectingMan agementFraudInPublicCompanies.pdf

[13] S.-M. Huang, D.C. Yen, L.-W. Yang, J.-S. Hua, An investigation of Zipf's Law for fraud detection, Decision Support Systems 46 (1) (2008) 70-83.

[14] Hoogs Bethany, Thomas Kiehl, Christina Lacomb and Deniz Senturk (2007). A Genetic Algorithm Approach to Detecting Temporal Patterns Indicative Of Financial Statement Fraud, Intelligent systems in accounting finance and management 2007; 15: 41 - 56, John Wiley \& Sons, USA, available at: www.interscience.wiley.com

[15] M.J. Cerullo, V. Cerullo, Using neural networks to predict financial reporting fraud: Part 1, Computer Fraud \& Security 5 (1999) 14-17.

[16] E. Koskivaara, Artificial neural networks in auditing: state of the art, The ICFAI Journal of Audit Practice 1 (4) (2004) 12-33.

[17] B. Busta, R. Weinberg, Using Benford's law and neural networks as a review procedure, Managerial Auditing Journal 13 (6) (1998) 356-366.

[18] H.C. Koh, C.K. Low, Going concern prediction using data mining techniques, Managerial Auditing Journal 19 (3) (2004) 462-476.

[19] Belinna Bai, Jerome yen, Xiaoguang Yang, False Financial Statements: Characteristics of china listed companies and CART Detection Approach, International Journal of Information Technology and Decision Making, Vol. 7, No. 2(2008), 339 - 359

[20] Juszczak, P., Adams, N.M., Hand, D.J., Whitrow, C., \& Weston, D.J. (2008). Off-the-peg and bespoke classifiers for fraud detectionll, Computational Statistics and Data Analysis, vol. 52 (9): 4521-4532

[21] A. Deshmukh, L. Talluru, A rule-based fuzzy reasoning system for assessing the risk of management fraud, International Journal of Intelligent Systems in Accounting, Finance \& Management 7 (4) (1998) 223 241.

[22] Wei Zhou, G. Kappor, Detecting evolutionary financial statement fraud, Decision Support Systems 50 (2011) $570-575$.

[23] P.Ravisankar, V. Ravi, G.Raghava Rao, I., Bose, Detection of financial statement fraud and feature selection using data mining techniques, Decision Support Systems, 50(2011) 491 - 500

[24] Johan Perols, Financial Statement Fraud Detection: An Analysis of Statistical and Machine Learning Algorithms, A Journal of Practice \& Theory 30 (2), 19 (2011), pp. 19-50

[25] Mieke Jans, Nadine Lybaert \& Koen Vanhoof. A Framework for Internal Fraud Risk reduction, an IT integrating business process: The IFR2 framework. The 
international Journal of Digital Accounting Research, 9, $1-29$.

[26] Ngai, E.W.T., Hu, Y., Wong, Y. H., Chen, Y., \& Sun, X. (2010). The application of data mining techniques in financial fraud detection: A classification framework and an academic review of literature, Decision Support System (2010), doi:10.1016/j.dss.2010.08.006

[27] Anuj Sharma \& Prabin Kumar Panigrahi, “ A review of financial Accounting Fraud Detection based on Data Mining Techniques", International Journal of Computer Application, Vol. 39 - No.1, Feb. 2012 pp. 37 - 47

[28] "Fraud, Waste, and Abuse - Prevention, Detection and Reporting for Federal, State, Local, and Tribal Administrators" United States Environmental Protection Agency (Office of Inspector General), www.epa.gov/oig

[29] Rezaee Z., Riley R. 2010. Financial statement fraud: prevention and detection. $2^{\text {nd }}$ Edition New York: John Wiley.

[30] ACFE, Tone at the top: How Management can prevent fraud in workplace, Available at: http://www.acfe.com/uploadedFiles/ACFE_Website/Con tent/documents/tone-at-the-top-research.pdf

[31] "Report of the National Commission on Fraudulent Financial Reporting", Retrieved June 07, 2012 from http://www.coso.org/Publications/NCFFR.pdf

[32] Fanning, K., Cogger, K., \& Srivastava, R. (1995). Detection of management fraud: a neural network approach. International Journal of Intelligent Systems in Accounting, Finance \& Management, vol. 4, no. 2, pp. 113-26, June 1995.
[33] Elkan, C. (2001). Magical Thinking in Data Mining: Lessons from COIL Challenge 2000. Proc. of SIGKDD01, 426-431

[34] Turban, E., Aronson, J.E., Liang, T.P., \& Sharda, R. (2007). Decision Support and Business Intelligence Systems, Eighth edition, Pearson Education, 2007

[35] Wang, S. (2010). A Comprehensive Survey of Data Mining-Based Accounting-Fraud Detection Research. International Conference on Intelligent Computation Technology and Automation, vol. 1, pp.50-53, 2010.

[36] Chien C.-F. and Chen L.-F.. Data mining to improve personnel selection and enhance human capital: A case study in high-technology industry. Expert Systems with Applications Vol 34, Issue I, Jan 2008 pp. 280-290.

[37] Han Jiawei \& Kamber Micheline, Data Mining: Concepts and Techniques, Morgan Koufmann Publishers

[38] Cressey, D.R. 1986. Why managers commit fraud. Australian and New Zealand Journal of Criminology. 19(4): 195-209.

[39] Albrecht W., Albrecht C., and Albrecht C. Fraud and corporate executives: Agency, stewardship and broken trust. Journal of Forensic Accounting 1524 - 5586 / vol. V (2004) pp. 109 - 130, R.T. Edwards Inc. , Printed in USA

[40] Z. Rezaee, Financial Statement Fraud-Prevention and Detection, John Wiley \&Sons, Inc., 2002. 